\title{
POLARIZATION DYNAMICS OF Pi2 PULSATIONS AT MIDLATITUDES DURING DEVELOPMENT OF SUBSTORMS IN THE AURORAL ZONE
}

\section{R.A. Rakhmatulin}

Institute of Solar-Terrestrial Physics SB RAS, Irkutsk, Russia,rav@iszf.irk.ru

\author{
A.Yu. Pashinin \\ Institute of Solar-Terrestrial Physics SB RAS, \\ Irkutsk,Russia,pash@iszf.irk.ru
}

\begin{abstract}
We examine the changes in the orientation of the major axis of the polarization ellipse of irregular geomagnetic pulsations $\mathrm{Pi2}$, observed at midlatitudes during a substorm disturbance developing in the auroral zone of the Russian Arctic sector. We have found the dependence of the polarization ellipse orientation on the longitude of a corresponding substorm. The results of current studies are compared with earlier results of similar studies using materials on the North American continent. We have concluded that the results
\end{abstract}

are similar in general, with a slight discrepancy which may be due to peculiarities of the geological structure of the earth crust in the Russian Arctic sector.

Keywords: magnetosphere, geomagnetic disturbances, auroral substorm, geomagnetic pulsations Pi2, polarization of geomagnetic pulsations, Russian Arctic sector, magnetic observatories.

\section{INTRODUCTION}

The onset of the substorm active phase in the auroral zone is followed by the generation of a broadband burst of irregular Pi2+Pi1B pulsations. At midlatitudes, Pi2 show as damped trains of oscillations with 45-200 s periods [Pudovkin et al., 1976; Koshelevsky et al., 1972] predominantly in the midnight sector of the magnetosphere [Raspopov, Troitskaya,1974; Kuwashima, 1981; Shiokawa et al., 2002]. Figure 1 presents dynamic spectra of irregular geomagnetic pulsations, recorded simultaneously at high and middle latitudes during the active phase of the substorm on March 7, 2006. It is clearly seen that at high latitudes there is a broadband burst of irregular Pi2+Pi1b pulsations; at middle latitudes, two spectral bands predominate $-\sim 35 \mathrm{~s}$ and more long-period ( $125 \mathrm{~s}$ ) components, as has been shown in our previous works on the results of experiments at the Norilsk meridian [Rakhmatulin, Petrovsky, 1994].

Previous studies of morphological characteristics of $\mathrm{Pi} 2$ pulsations at midlatitudes, in particular the behavior of polarization characteristics of oscillations, have shown that the major axis of the $\mathrm{Pi} 2$ polarization ellipse in a horizontal plane at midlatitudes changes its direction from east to west when passing through the midnight meridian [Raspopov, Troitskaya, 1974]. These studies have been carried out based on extensive statistical material but without regard to specific conditions, which cause excitation of a certain burst of irregular $\mathrm{Pi} 2$ pulsations, and to the longitude of the position of the active region in the auroral zone.

We have conducted a study to determine, using data from a mid-latitude station, how the major axis of the polarization ellipse of irregular $\mathrm{Pi} 2$ pulsations changes its direction in space during development of a substorm. We figured out whether the longitude of the region of auroral disturbances influences the polarization ellipse orientation or not, since it is known that during development of auroral disturbances the active region moves from east to west.

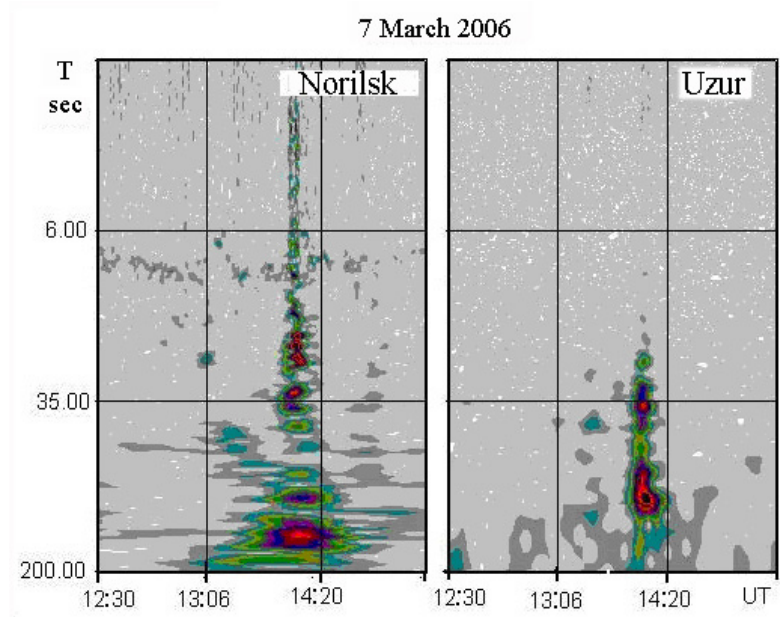

Figure 1. Dynamic spectra of Pi2 pulsations observed simultaneously at high (Norilsk station) and middle (Uzur station) latitudes during the active substorm phase

Our purpose here is to determine how the major axis of $\mathrm{Pi} 2$ polarization ellipse changes its direction at midlatitudes when the active region moves in the auroral zone in the azimuthal direction.

\section{DATA \\ AND METHOD OF ANALYSIS}

Solving this problem requires coordinated observations of magnetospheric processes at high and middle latitudes. There can be two approaches to the study. The first is an analysis of the development of a substorm based on magnetograms from one high-latitude station and pulsation data from the global network of midlatitude observatories. The analysis is exemplified in Figure 2 representing pulsation records made at the network of mid-latitude observatories during the onset of a substorm over Tixie station. We present fragments of analog records of geomagnetic pulsations and 
their corresponding dynamic oscillation spectra; figures indicate geomagnetic longitudes of the stations. Below is a fragment of the magnetogram from Tixie station. The beginning of the active substorm phase at this station at 14:18 UT is accompanied by the generation of irregular $\mathrm{Pi} 2$ pulsations, reliably detected at all the stations. Almost all the oscillations begin at the same time and have the form of a classical train. Note that in fact we deal with global excitation of $\mathrm{Pi} 2$ pulsations at midlatitudes. We have discussed this in our previous papers [Rakhmatulin et al., 2000, 2005].

The second approach involves the analysis of the excitation of pulsations when substorms occur in different longitudinal sectors, using data from one mid-latitude station and magnetograms from all auroral stations (Figure 3).

Obviously, the second approach is easier to implement, since magnetograms from high-latitude stations are more available than data on geomagnetic pulsations from the global network of mid-latitude observatories. It should be added that the high-latitude observatories that record magnetic field variations are equipped with almost identical hardware; the same cannot be said of the equipment for recording geomagnetic pulsations.

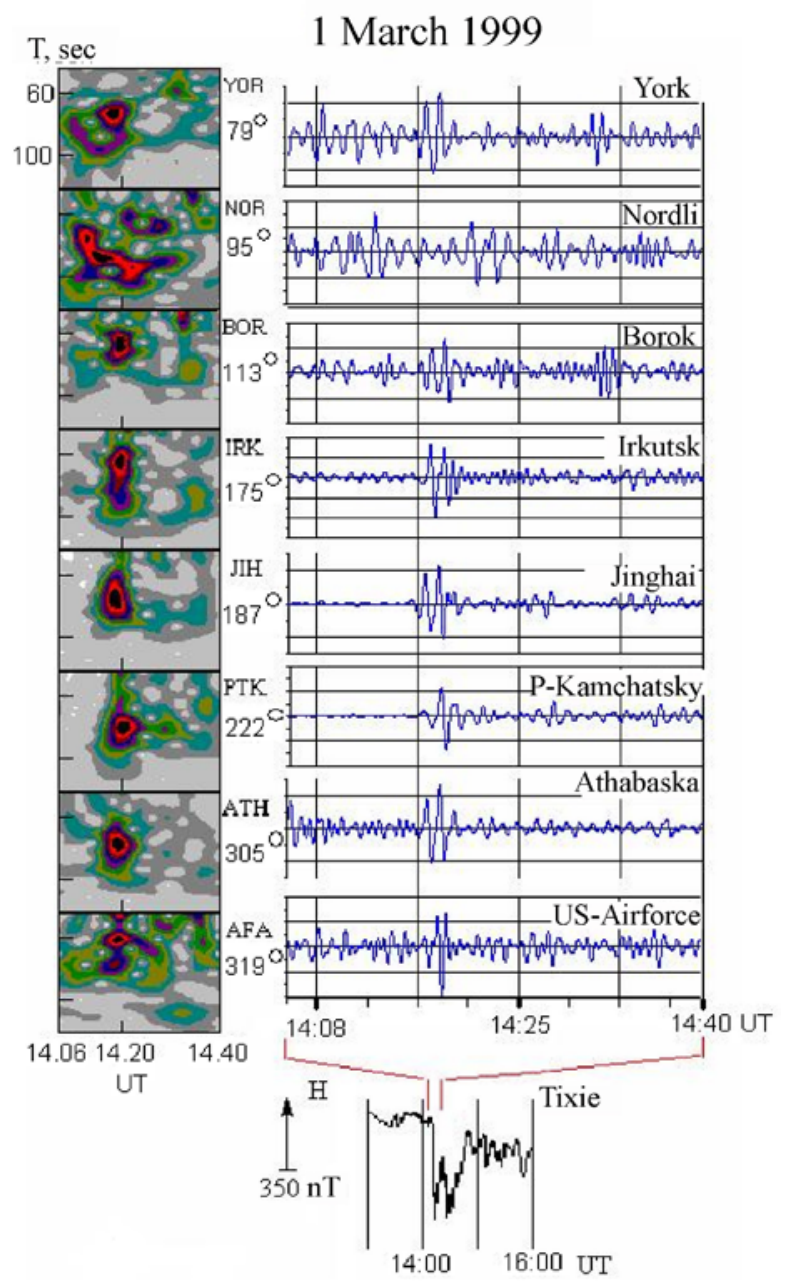

Figure 2. Pi2 pulsations at midlatitudes during the active substorm phase in the night sector over Tixie station. To the left are dynamic spectra; to the right, fragments of an analog recording of pulsations; at the bottom, the $H$ component of the magnetogram from Tixie station.
Table 1

Coordinates of observatories used for the analysis

\begin{tabular}{|c|c|c|c|}
\hline No. & Observatory & $\begin{array}{c}\text { Geographic } \\
\text { latitude }\end{array}$ & $\begin{array}{c}\text { Geographic } \\
\text { longitude }\end{array}$ \\
\hline 1 & $\begin{array}{c}\text { Irkutsk } \\
\text { (vlg. Patrony) }\end{array}$ & $52^{\circ} 09^{\prime} \mathrm{N}$ & $104^{\circ} 28^{\prime} \mathrm{E}$ \\
\hline 2 & Uzur & $53^{\circ} 19^{\prime} \mathrm{N}$ & $107^{\circ} 44^{\prime} \mathrm{E}$ \\
\hline 3 & Norilsk & $69^{\circ} 21^{\prime} \mathrm{N}$ & $88^{\circ} 21^{\prime} \mathrm{E}$ \\
\hline 4 & Istok & $70^{\circ} 01^{\prime} \mathrm{N}$ & $88^{\circ} 00^{\prime} \mathrm{E}$ \\
\hline 5 & Mondy & $51^{\circ} 37^{\prime} \mathrm{N}$ & $100^{\circ} 54^{\prime} \mathrm{E}$ \\
\hline 6 & Dixon & $73^{\circ} 33^{\prime} \mathrm{N}$ & $80^{\circ} 34^{\prime} \mathrm{E}$ \\
\hline 7 & Tixie & $72^{\circ} 35^{\prime} \mathrm{N}$ & $129^{\circ} 00^{\prime} \mathrm{E}$ \\
\hline 8 & Pebek & $70^{\circ} 06^{\prime} \mathrm{N}$ & $170^{\circ} 56^{\prime} \mathrm{E}$ \\
\hline 9 & Lovozero & $69^{\circ} 58^{\prime} \mathrm{N}$ & $35^{\circ} 01^{\prime} \mathrm{E}$ \\
\hline 10 & Amderma & $69^{\circ} 29^{\prime} \mathrm{N}$ & $61^{\circ} 26^{\prime} \mathrm{E}$ \\
\hline 11 & Soroa (Cuba) & $22^{\circ} 48^{\prime} \mathrm{N}$ & $277^{\circ} 00^{\prime} \mathrm{E}$ \\
\hline
\end{tabular}

Therefore, to achieve our purposes we have chosen the second approach. Table 1 lists geographic coordinates of the stations used in the analysis.

Parameters of Pi2 pulsations (amplitude, spectrum, orientation of the major axis of the polarization ellipse) are evaluated from observations made at Mondy and Uzur mid-latitude stations; in some cases we use data on geomagnetic pulsations acquired at Norilsk and Istok high-latitude stations. The pulsation data are compared with the data on the development of auroral substorms at different longitudes of the Russian Arctic sector. Substorm disturbances are localized using magnetograms from Arctic stations, taken from the website of the World Data Center (WDC, Kyoto) [http://wdc.kugi.kyoto-u.ac.jp/plot_realtime/quick /index.html].

The experimental data are analyzed as follows. We use data from the high-latitude observatories to select cases (intervals) when the disturbances were located at one of the zonal stations, i.e. the value of the $H$ component at this station far exceeds disturbances at other stations), or when the disturbances move from east to west during the development of the global disturbance [Kuwashima, 1981]. Then, we utilize records of geomagnetic pulsations from Mondy or Uzur stations to identify moments of onsets of all Pi2 trains within the selected intervals. Examples of the comparison of such data are given in Figure 3, which illustrates $H$ components of magnetograms from high-latitude observatories $(a)$ and analog recordings of geomagnetic pulsations $(b)$.

It is seen that the region of substorm activity moves from east to west (the onset of disturbance at each station is indicated by an arrow). The beginning of the substorm disturbance activation at each station is accompanied by excitation of irregular Pi2 pulsations at midlatitudes (Uzur observatory).

To process the experimental data, we have devised a special method. Figure 4 shows a sequence of operations in the experimental data processing.

Using the spectral-time analysis program (SWAN), we construct the dynamic spectrum of the oscillations of interest (Figure 4, a). We next separate the desired portion of data and process it with a special filter, which cuts out frequencies corresponding to the dynamic spectrum of a signal. Then we construct an oscillogram of the oscillations (Figure $4, b$ ). 

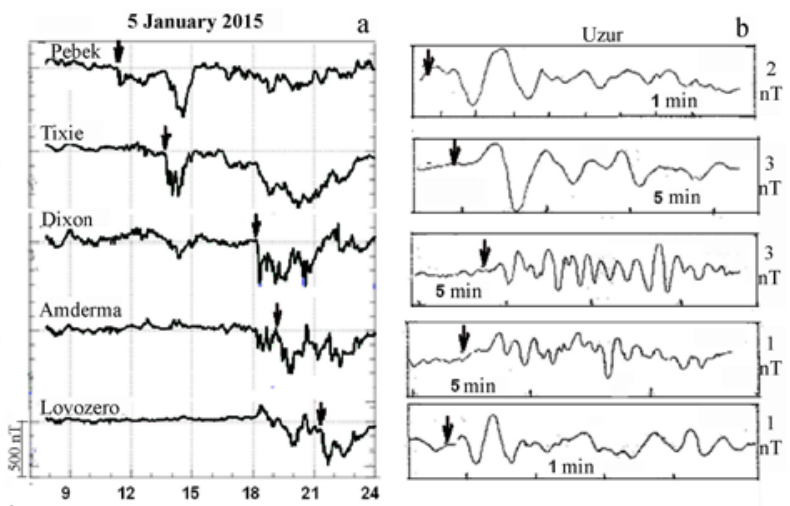

Figure 3. Development of magnetic disturbances on January 5, 2015: $H$ component according to data from auroral stations $(a)$; geomagnetic pulsations in 1-min and 5-min scales at Irkutsk station (Uzur) (b); (arrows indicate onsets of Pi2 geomagnetic pulsations at Irkutsk station; on analog recordings of pulsations is the time of the beginning of oscillations in each event)

Finally, to identify the polarization characteristics, we construct a polarization ellipse (Figure 4, c) and measure the tilt angle $\alpha$ of the major axis of the polarization ellipse to the horizontal axis (east-west direction).

\section{RESULTS}

We have analyzed several tens of cases, some of which are in Table 2. The first column lists names of the auroral stations whose magnetic data are used in this work; the second column shows geographic coordinates of these stations; the third and fourth columns contain date and time of the substorm onset at auroral latitudes and of the beginning of the corresponding train of irregular Pi2 pulsations over Mondy observatory.

The last column represents the values of the angle $\alpha$ calculated from polarization ellipses.

These experimental data are used to plot the angle $\alpha$ as a function of longitude of the development of the corresponding substorm (Figure 5).

Let us now turn to the results of earlier studies we have carried out in cooperation with Cuban colleagues, using observations made in North America. We conducted such studies in the 1990s under the Program of Cooperation between Academies of Sciences of Socialist Countries on Planetary Geophysics (CAPG) [Costa et al., 1984]. We used data on geomagnetic pulsations from Cuban Soroa station, and data on magnetic field variations at auroral latitudes were taken from WDC Newsletters [Allen et al., 1977].

After a series of experiments, we have obtained the dependence of the orientation of the main angle of the Pi2 polarization ellipse for North America (Figure 6).

The comparative analysis of data obtained from the American and Russian Arctic sectors is shown in Figure 7 . Note that the zero point on the longitude scale corresponds to the meridians of Mondy (100 $\left.54^{\prime} \mathrm{E}\right)$ and Soroa $\left(277^{\circ} 00^{\prime} \mathrm{E}\right)$.

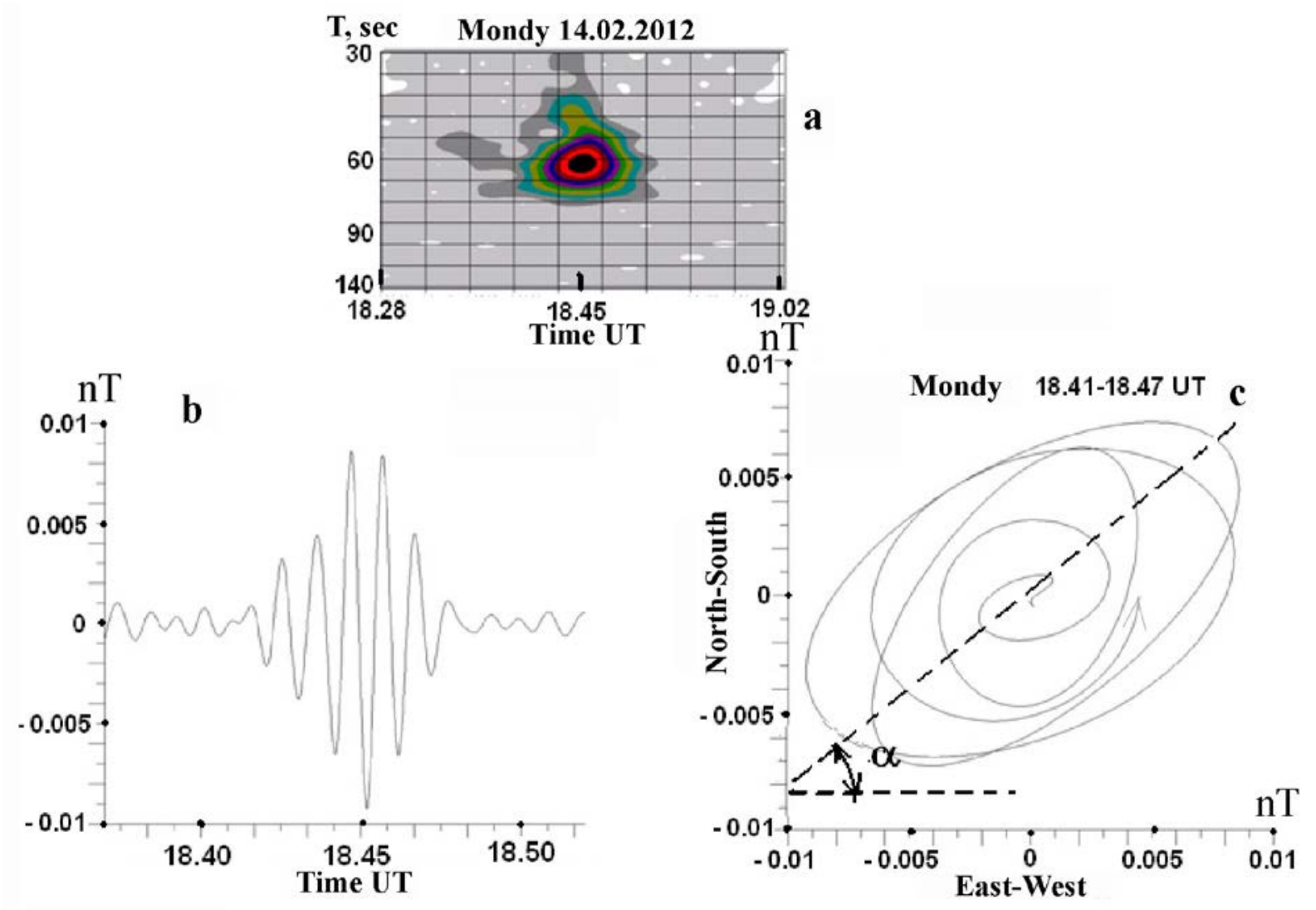

Figure 4. Procedure of experimental data processing (see the text) 


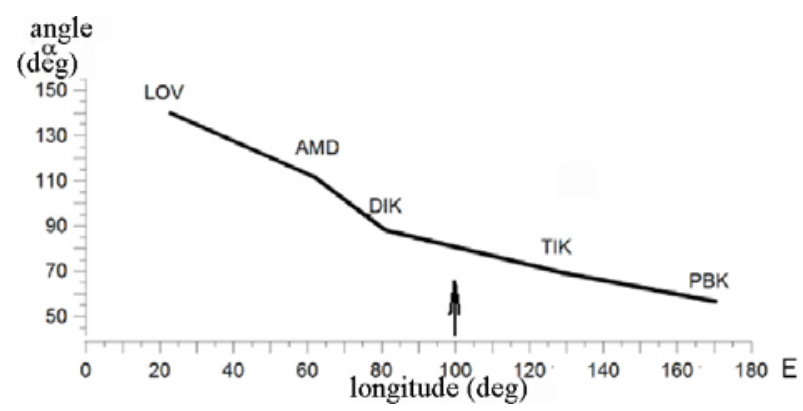

Figure 5. Tilt angle of the major axis of the $\mathrm{Pi} 2$ polarization ellipse as a function of longitude of auroral substorm development. The arrow marks the meridian of Mondy station

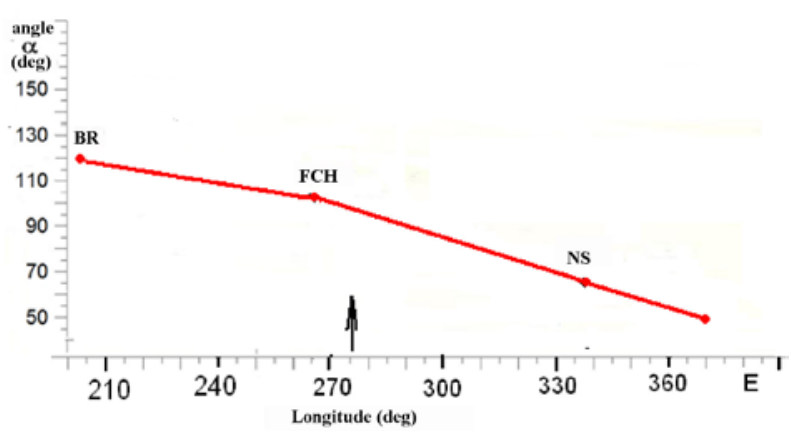

Figure 6. Orientation of the major axis of the $\mathrm{Pi} 2$ polarization ellipse in Soroa (angle $\alpha$ ) as a function of longitude of the magnetic bay at high latitudes, according to the data from Barrow (BR), Fort Churchill (FCH), and Narsarsuaq (NS) stations. The arrow marks the meridian of Soroa station

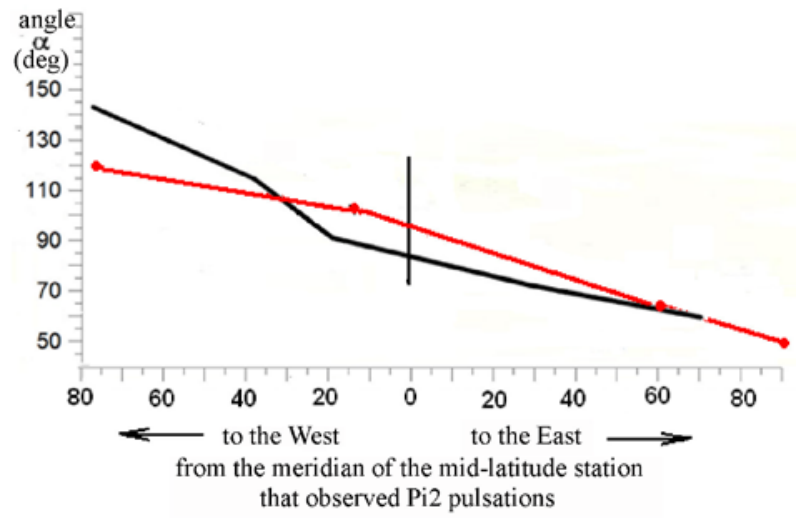

Figure 7. Comparative analysis of the tilt angle of the major axis of the $\mathrm{Pi} 2$ polarization ellipse as a function of longitude of the respective substorm development, according to the data from of the Russian (black line) and US (red line) Arctic sectors

The analysis of the dependences shown in Figure 7 allows the following conclusion. The dependence of the angle of polarization ellipse orientation on the longitude of substorm development is similar for the North American and Eurasian continents. There are slight discrepancies which can be caused by the influence of geological structures and by the presence of significant magnetic anomalies on the Taimyr Peninsula [Krakovetsky et al., 1982; Popov et al., 2010].

Table 2

\begin{tabular}{|c|c|c|c|c|}
\hline Observatory & $\begin{array}{l}\text { Geographic } \\
\text { coordinates }\end{array}$ & Date & $\begin{array}{c}\text { Time of onset } \\
\text { of substorm and Pi2, } \\
\text { UT }\end{array}$ & $\begin{array}{c}\text { Angle } \alpha \text {, } \\
\text { deg }\end{array}$ \\
\hline \multirow{6}{*}{ Pebek (PBK) } & \multirow{6}{*}{$70^{\circ} 06^{\prime} \mathrm{N} 170^{\circ} 56^{\prime} \mathrm{E}$} & January 10, 2015 & 14.10 & 55 \\
\hline & & January 12, 2015 & 11.47 & 60 \\
\hline & & March 05, 2015 & 11.46 & 60 \\
\hline & & January 27, 2015 & 12.30 & 50 \\
\hline & & January 22, 2015 & 12.15 & 60 \\
\hline & & January 10, 2015 & 14.10 & 55 \\
\hline \multirow{7}{*}{ Tixie (TIK) } & \multirow{7}{*}{$72^{\circ} 35^{\prime} \mathrm{N} 129^{\circ} 00^{\prime} \mathrm{E}$} & January 10, 2015 & 12.20 & 75 \\
\hline & & January 26, 2015 & 16.37 & 70 \\
\hline & & January 30, 2015 & 16.18 & 70 \\
\hline & & January 30, 2015 & 17.27 & 60 \\
\hline & & March 05, 2015 & 15.15 & 70 \\
\hline & & December 23, 2014 & 20.44 & 70 \\
\hline & & January 22, 2015 & 11.07 & 70 \\
\hline \multirow{5}{*}{ Dixon (DIK) } & \multirow{5}{*}{$73^{\circ} 33^{\prime} \mathrm{N} 80^{\circ} 34^{\prime} \mathrm{E}$} & January 12, 2015 & 15.40 & 85 \\
\hline & & January 30, 2015 & 18.01 & 90 \\
\hline & & January 30, 2015 & 18.09 & 90 \\
\hline & & March 05, 2015 & 16.15 & 85 \\
\hline & & January 22, 2015 & 19.06 & 90 \\
\hline \multirow{3}{*}{ Amderma (AMD) } & \multirow{3}{*}{$69^{\circ} 29^{\prime} \mathrm{N} 61^{\circ} 26^{\prime} \mathrm{E}$} & January 26, 2015 & 17.00 & 120 \\
\hline & & January 30, 2015 & 19.50 & 110 \\
\hline & & January 22, 2015 & 17.45 & 105 \\
\hline Lovozero (LOV) & $69^{\circ} 58^{\prime} \mathrm{N} 35^{\circ} 01^{\prime} \mathrm{E}$ & January 30, 2015 & 20.12 & 140 \\
\hline
\end{tabular}



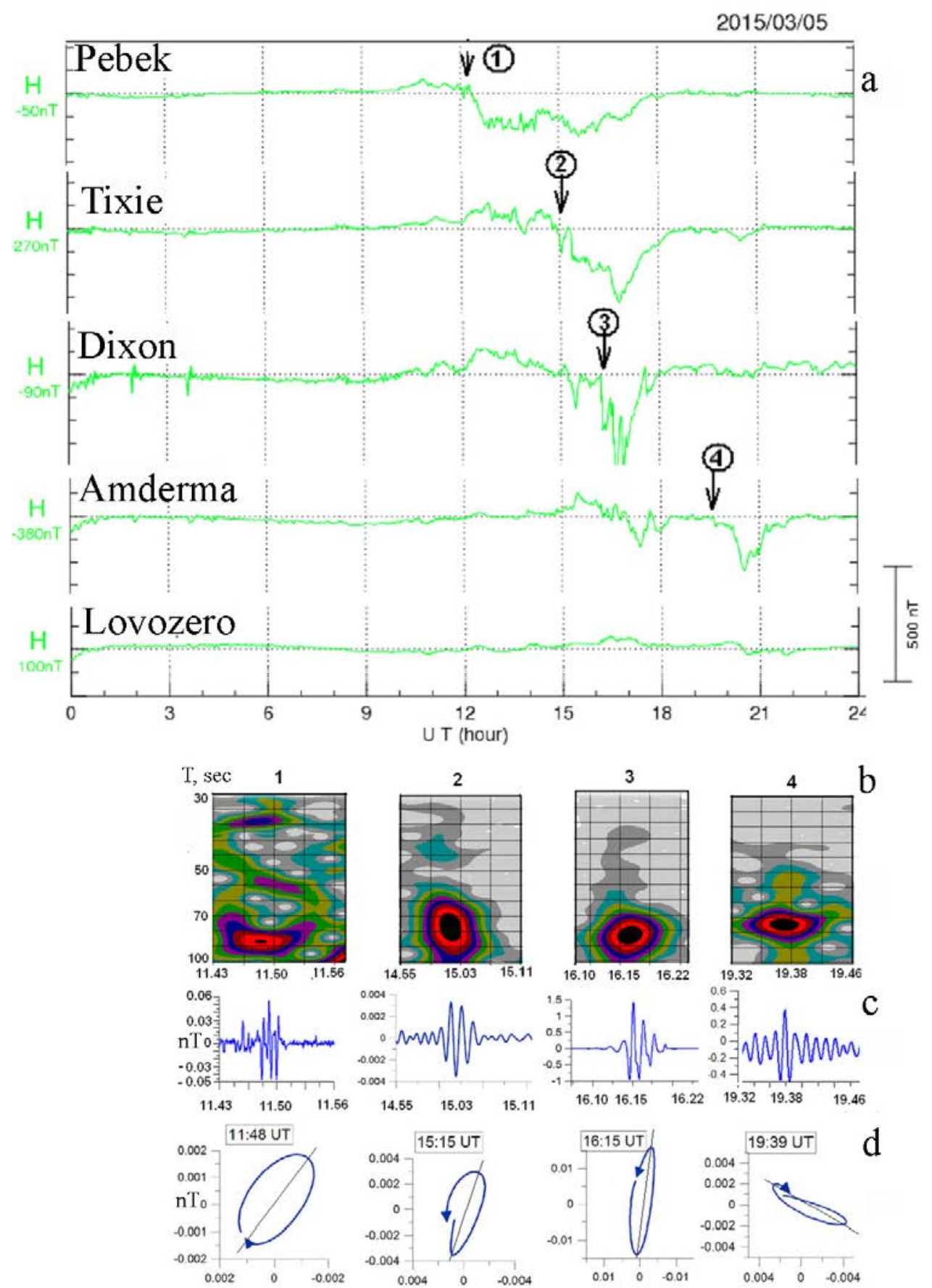

Figure 8. Development of magnetic disturbances in the auroral zone $(a)$ and synchronous observations of irregular pulsations | at Mondy Observatory: dynamic spectra $(b)$; analog recordings $(c)$; polarization ellipses of irregular pulsations $(d)$

\section{EXAMPLE OF MONITORING OF TRAVELING ACTIVE SUBSTORM REGION}

The proposed method can be illustrated using the example of the development of a number of consecutive substorms in the auroral zone with a gradual movement of the disturbance region from east to west on March 5, 2015 (Figure 8). It can be seen that as the disturbances develop and the active region moves, the major axes of polarization ellipses turn as if they "track" the movement of the active region.

\section{CONCLUSION}

From the analysis of the research, we can draw the following conclusion about the possible practical application of the results. The dependences shown in Figure 7 allow us to estimate, with some degree of reliability, the longitude of the onset of substorm development in the auroral zone from observations of irregular pulsations at midlatitudes. This can be applied to those cases where, for whatever reason, there are no recordings of magnetic field variations at high latitudes or a substorm occurs in a region where there is no magnetic observatory. 
Finally, note that this method is valid for weak and moderate magnetic activity. During high magnetic activity, a disturbance region can cover a space up to 90 $120^{\circ} \mathrm{E}$, and in such a situation it is difficult to determine the predominant direction of the major axes of $\mathrm{Pi} 2$ polarization ellipses.The study was performed with budgetary funding of Basic Research program II.16; the work of A.Y. Pashinin was supported by RFBR grant 16-05-00631. The results were obtained using the equipment of Center for Common Use «Angara» [http://ckp-rf.ru/ckp/3056/].

\section{REFERENCES}

Allen J., Abston C.C., Morris L.D. Geomagnetic Data for February, March 1976. Rep.UAG-62, 63 . World Data Center for Solar-Terr. Phys. 1977, p. 55.

Costa A.D., Parkhomov V. A., Rakhmatulin R.A., Rodriguez F. Influence of longitudinal localization of a substorm on low-latitude Pi2 parameters. Issledovaniya po geomagnetizmu, aeronomii i fizike Solntsa [Res. on Geomagnetism, Aeronomy and Solar Phys.]. 1984, iss. 70, pp. 171-177. (In Russian).

Koshelevsky V.K., Raspopov O.M., Starkov G.V. The connection of parameters of geomagnetic pulsations $\mathrm{Pi} 2$ with processes in the auroral zone. Geomagnetizm i aeronomiya. [Geomagnetism and Aeronomy]. 1972, vol. 12, no. 5, pp. 886891. (In Russian).

Krakovetsky Yu.K., Platonov O.I., Popov L.N., Doronina I.P. Aurora spatial distribution of a polar light and its relation with the Earth crust structure. Issledovaniya po geomagnetizmu, aeronomii i fizike Solntsa [Res. on Geomagnetism, Aeronomy and Solar Phys.]. 1982, iss. 62, pp. 155-164. (In Russian).

Kuwashima M.A. A model of magnetic Pi2 pulsations based on ULF observation from high to middle latitudes on the ground. Memoirs of National Institute of Polar Res. 1981. Spec. № 16, pp. 15-21.

Popov L.N., Krakovetsky Yu.K., Zakharenko V.N., Parnachev V.P., Odintsov N.M. On revealing geological structures by the distant method of ionosphere-telluric profiling (by example of northern districts of Siberia). Vestnik Tomskogo gosudarstvennogo universiteta. Ser. Nauki o Zemle [Tomsk State University Bull. Ser. Earth Sci.]. 2010, no. 399, pp. 205209. (In Russian).
Pudovkin M.I., Raspopov O.M., Kleymenova N.G. Vozmushcheniya electromagnitnogo polya Zemli. Chast 2. [Disturbances of the Earth's electromagnetic field. Part 2]. Leningrad, LGU Publ., 1976, 270 p. (In Russian).

Rakhmatulin R.A., Pashinin A.Y., Hayashi K. The observation of global $\mathrm{Pi} 2$ pulsation in the mid-latitudes during small substorms. Proc. the 5 Intern. Conference on Substorms. St. Petersburg, Russia, July 2000, ESA SP-443, pp. 561-564.

Rakhmatulin R.A., Pashinin A.Yu., Zhao Hua. An investigation of near-equatorial geomagnetic $\mathrm{Pi} 2$ pulsations. Chinese J. Space Sci. 2005, vol. 25, no 5, pp. 430-432.

Rakhmatulin R.A., Petrovsky M.A. Research into dynamic spectra of high-latitude Pi2-pulsations. Issledovaniya po geomagnetizmu, aeronomii i fizike Solntsa [Res. on Geomagnetism, Aeronomy and Solar Phys.]. 1994, iss. 103, pp. 49-56. (In Russian).

Raspopov O.M., Troitskaya V.M. Razvitie subburi v geomagnitnykh pulsatsiyakh. Vysokoshirotnye geofizicheskie yavleniya [Substorm Development in Geomagnetic Pulsations. High-latitude Geophysical Phenomena]. Leningrad, 1974, pp. 232-247. (In Russian).

Shiokawa K., Yumoto K., Olson J.V. Multiple auroral brightening and associated Pi2 pulsations. Geophys. Res. Lett. 2002, vol. 29, no 11, pp. 32/1-32/4.

URL: http://wdc.kugi.kyoto-u.ac.jp/plot_realtime/quick/index. html (accessed November 23, 2016).

URL: http://ckp-rf.ru/ckp/3056 (accessed November 23, 2017).

How to cite this article

Rakhmatulin R.A., Pashinin A.Yu. Polarization dynamics of Pi2 pulsations at midlatitudes during development of substorms in the auroral zone. Solar-Terrestrial Physics. 2018. vol. 4, iss. 3, pp. 46-51. DOI: $10.12737 /$ stp-43201807. 